\title{
JECH
}

\section{Is leg length a biomarker of childhood conditions in older Chinese women? The Guangzhou Biobank Cohort Study}

C M Schooling, C Q Jiang, M Heys, W S Zhang, X Q Lao, P Adab, B J Cowling, G N Thomas, K K Cheng, T H Lam and G M Leung

J Epidemiol Community Health 2008;62;160-166

doi:10.1136/jech.2006.058917

Updated information and services can be found at:

http://jech.bmj.com/cgi/content/full/62/2/160

These include:

References This article cites 47 articles, 21 of which can be accessed free at: http://jech.bmj.com/cgi/content/full/62/2/160\#BIBL

Rapid responses You can respond to this article at:

http://jech.bmj.com/cgi/eletter-submit/62/2/160

Email alerting Receive free email alerts when new articles cite this article - sign up in the box at service the top right corner of the article

Notes

To order reprints of this article go to:

http://journals.bmj.com/cgi/reprintform

To subscribe to Journal of Epidemiology and Community Health go to:

http:/journals.bmj.com/subscriptions/ 


\title{
Is leg length a biomarker of childhood conditions in older Chinese women? The Guangzhou Biobank Cohort Study
}

\author{
C M Schooling, ${ }^{1}$ C 0 Jiang, ${ }^{2}$ M Heys, W S Zhang, ${ }^{2}$ X 0 Lao, ${ }^{1}$ P Adab, ${ }^{3}$ B J Cowling, \\ G N Thomas, ${ }^{1}$ K K Cheng, ${ }^{3}$ T H Lam, ${ }^{1}$ G M Leung ${ }^{1}$
}

${ }^{1}$ Department of Community Medicine, and School of Public Health, The University of Hong Kong, Hong Kong SAR, China;

${ }^{2}$ Guangzhou Occupational Diseases Prevention and Treatment Centre, Guangzhou Number 12 Hospital,

Guangzhou, China; ${ }^{3}$ Department of Public Health and Epidemiology, University of Birmingham, UK

Correspondence to: Professor T H Lam, Department of Community Medicine, and School of Public Health, The University of Hong Kong, 21

Sassoon Road, Pokfulam, Hong

Kong; commed@hkucc.hku.hk

Accepted 20 March 2007

\section{ABSTRACT}

Objective: In developed western populations longer legs have been shown to be a biomarker of better early childhood conditions. It was hypothesised that in transitioning populations better childhood conditions may bring forward puberty and thus decrease leg length, counteracting the overall positive effect of a favourable childhood environment on leg growth.

Design: Structural equation modelling was used to assess the interrelationship of age, education, father's job, age of menarche and leg length in a cross-sectional sample of 7273 Chinese women aged at least 50 years from the Guangzhou Biobank Cohort Study.

Results: Leg length had no significant association with education or father's occupation on bivariable testing. After including age of menarche in the model, education was associated with longer legs $(0.45 \mathrm{~cm}$ longer per 10 years of education, $95 \% \mathrm{Cl} 0.20$ to 0.71 ). Education was also associated with younger age of menarche $(1.21$ years younger per 10 years of education, $95 \% \mathrm{Cl} 1.09$ to 1.34), which was in turn associated with shorter legs $(0.23 \mathrm{~cm}$ shorter per year of menarche earlier, $95 \% \mathrm{Cl}$ 0.18 to 0.27$)$.

Conclusions: In older Chinese women leg length is not a universal biomarker of childhood conditions, when proxied by her educational level and father's occupation.

Nutritionally driven epigenetic influences operating over generations may constrain growth in very recently developed populations. Given the impact of childhood conditions on health, and the dearth of long-term records outside the industrialised world, a greater understanding of the influences on growth in the developing world is required.

Environmental factors throughout the life course have long been recognised as relevant to adult health. ${ }^{1}$ Early life exposures have been shown to increase the risk of many adult chronic diseases. ${ }^{2}$ Relationships between early life conditions and long-term health are most easily explored in established long-term prospective cohorts or by using record linkage to follow up historical cohorts. These are, however, scarce and limited resources that largely do not exist outside of postindustrial economies, which precludes potentially key evidence from countries with very different childhood exposures and patterns of adult disease. Biomarkers of childhood exposures that can be assessed in adults provide an alternative approach for elucidating relationships between childhood conditions and adult health within a reasonable time frame in more recently developed or developing populations.

Leg length has been demonstrated to be a reliable biomarker of better early childhood conditions, ${ }^{3-5}$ in developed countries where improved living conditions over many generations since the Industrial Revolution have been reflected in gradual increases in height, mainly attributable to longer legs. ${ }^{6}$ Moreover, improved childhood conditions have been reflected in increases in the tempo of sexual maturation ${ }^{67}$ resulting in earlier puberty, although in women the secular trend may have plateaued at a physiological minimum. ${ }^{6}$ Correspondingly low childhood socioeconomic status (proxied by own education or father's social class) is usually associated with shorter height, ${ }^{8-11}$ although the association with older age of menarche may be more obvious in developing settings. ${ }^{12-14}$ Outside of the postindustrialised world the historically more recent improvements in living standards mean that improved childhood conditions may affect both the tempo of maturation and the amount of growth, potentially making leg length a less sensitive marker of childhood conditions in these populations, because the higher levels of oestrogen associated with earlier puberty cause growth of the long bones in particular to cease..$^{15}{ }^{16}$ Very sudden improvements in living conditions between generations can bring forward puberty and thereby decrease leg length, as seen in children adopted from developing to developed countries. ${ }^{17} 18$ These children are typically growth restricted at adoption, then often experience catch-up growth that may trigger early puberty, ${ }^{19}$ in which skeletal age advances beyond chronological age and skeletal growth ceases at an earlier chronological age than would otherwise occur. Premature termination of skeletal growth mainly affects the legs. To determine the validity of leg length as a biomarker of childhood conditions outside of long-term industrialised populations, we used data from Guangzhou, the capital of Guangdong province in southern China.

\section{Sociohistorical context}

China is currently experiencing very rapid economic growth. Before the establishment of The People's Republic of China (PRC) in 1949, however, living standards were similar to pre-industrial Europe. ${ }^{20}{ }^{21}$ Some growth around the treaty ports along the eastern seaboard (eg Shanghai and to a lesser extent Guangzhou) in the first half of the 20 th century was reported, ${ }^{22}{ }^{23}$ but there was little 
industrialisation in Guangzhou. ${ }^{24}$ Male height in southern China in the early 20th century was similar to height in France at its pre-industrial nadir. ${ }^{25-28}$ Therefore for older adults currently living in Guangzhou, the stage of economic development during childhood was probably similar to pre-industrial or the very early stages of industrial development in Europe around the late 18th or early 19th century.

\section{Hypothesis}

Figure 1 shows the models used to investigate our hypothesis that the relationship between leg length and childhood conditions might be affected by age of menarche in this setting. First, components of height only were related to childhood conditions (model a). Second, childhood conditions impacted both leg length and age of menarche, and age of menarche in turn impacted leg length (model b).

\section{MATERIALS AND METHODS}

The Guangzhou Biobank Cohort Study is an ongoing collaboration between the Guangzhou No. 12 Hospital, and the Universities of Hong Kong and Birmingham, which was established to examine determinants of health prospectively, and has been described in detail elsewhere. ${ }^{29}$ Briefly, recruitment of participants aged 50 years and over draws from the Guangzhou Health and Happiness Association for the Respectable Elders (GHHARE), a community social and welfare association unofficially aligned with the municipal government whose membership is open to anyone for a monthly fee of $¥ 4$ (US50 cents). Approximately 7\% of permanent Guangzhou residents aged 50 years and over are members of GHHARE, of whom $11 \%$ were selected for this study. Our participants have similar rates of diabetes and hypertension to a nationally representative urban sample of the same age. ${ }^{29}$ Participants underwent a half-day detailed medical interview and a physical examination in 2003-2004. The Guangzhou Medical Ethics Committee of the Chinese Medical Association approved the study and all participants gave written, informed consent.

\section{Components of height and age of menarche}

Standing height and sitting height were measured to the nearest $0.1 \mathrm{~cm}$ in light clothing without shoes. One research nurse was allocated to height measurement throughout the study and followed a detailed protocol using one standard set of equipment and the same low stool for sitting height. Initial training was provided by the principal investigators. Leg length was taken as the difference between standing height and sitting height. Age of menarche was recorded in years.

Height in older individuals is not always a good estimator of stature at adulthood, as a result of shrinkage with age and illhealth, such as osteoporosis, which mainly affects the trunk. Leg length is less subject to change during adulthood. Age of menarche is potentially subject to random recall bias. Reliability was confirmed 6 months into recruitment by recalling 200 randomly selected participants. The intraclass correlation coefficient for age of menarche was 0.92 . The kappa value for education was 0.90 .

\section{Childhood living conditions}

Measures of childhood living conditions, such as diet, housing, sanitation or clothing, were not available for these women. In developing countries low family socioeconomic status reduces the child's educational attainment, ${ }^{30}$ because of the expense of education and of foregoing an economic contribution to the household. China was similar to other developing countries before 1949, and social restructuring after the establishment of the People's Republic of China did not eliminate inequalities in education until possibly the Cultural Revolution, ${ }^{31}{ }^{32}$ when almost all these women had completed their education. We used the woman's highest school level reached and her father's occupation as proxies for childhood conditions. There is no commonly used classification for Chinese occupations. We classified occupations as manual (agricultural worker, factory worker, sales and service worker) and non-manual (military and police, administrator/manager and professional/technical).

\section{Statistical analysis}

Multiple linear regression was used to assess the trends in height and its components by age, education and age of menarche. Structural equation modelling (SEM) was used to assess the interrelationships between age, childhood living conditions, age of menarche and each component of height. We used the two models described previously in fig 1. First, we retained education, father's job and birth year as separate observed variables, with education a continuous variable representing the approximate number of years of education for each level of attainment, as in table 1 . We used a weighted least squares estimate, because father's job was dichotomous. Second, we combined education, father's job and year of birth into a latent variable representing childhood conditions.

We examined whether relationships were consistent across age groups ( $<65$ years and $\geqslant 65$ years), from the significance of interaction terms and the heterogeneity of effect across strata. Results were considered statistically significant when two-tailed $\mathrm{p}<0.05$.

Almost half of the women (49.4\%) were unable to give a classifiable father's occupation. Multiple imputation is the statistical gold standard in this situation; as the assumptions required for validity of a complete case analysis are a superset of those required for validity of a multiple imputation analysis. ${ }^{33}$ Father's occupation was predicted on the basis of a flexible additive regression model with predictive mean matching ${ }^{34}$ incorporating data on age, education, longest held occupation, current personal income, leg length, seated height and age of menarche. We imputed missing values 10 times and analysed the 10 complete datasets separately. We summarised the results into single estimated beta-coefficients with confidence intervals (CI) and $p$ values adjusted for the missing data uncertainty. ${ }^{33}$ For comparison we also carried out a complete case analysis and an analysis without father's occupation.

\section{RESULTS}

Of the 7349 women recruited, 22 were missing leg length and 54 were missing age at menarche, giving 99\% (7273) with complete data on the variables of interest apart from father's job. The women were aged from 50 to 93 years, with a mean of 64.0 years and a standard deviation (SD) of 6.0 years. The mean age of menarche was 15.4 years (SD 2.1 years).

Table 1 shows the associations of age (expressed as birth years), education, father's job and age of menarche with height and its components. For simplicity the early ages of menarche (12 years or less) and the late ages of menarche (19 years and older) were grouped. Leg length had little relationship with age for those born up until 1949, although the very small number born after 1950 appeared to have longer legs. This difference was, however, not statistically significant. Education had little relationship with leg length for the majority of women (79.4\%) 
Figure 1 Possible models linking childhood conditions to components of height.

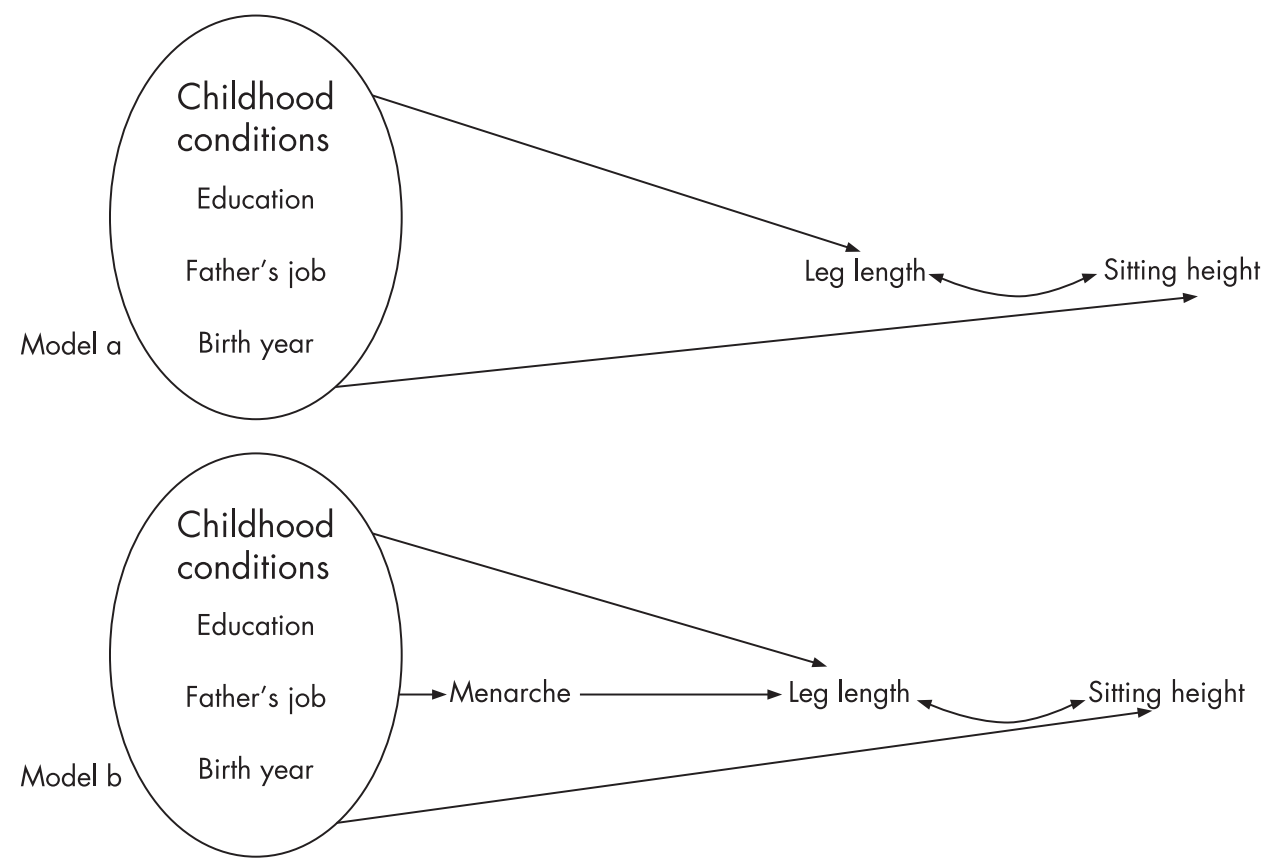

whose highest educational level was less than primary $(17 \%)$, primary $(40 \%)$ or junior middle school $(22 \%)$. In these three groups leg length was almost identical and lowest in the middle group with primary education. For the minority of women with higher levels of education, however, leg length increased with education. Nevertheless, the overall linear trend was not

Table 1 Mean height and its components by age, education, father's job and age of menarche for 7273 women in the Guangzhou Biobank Cohort Study

\begin{tabular}{|c|c|c|c|c|}
\hline & \multirow{2}{*}{$\begin{array}{l}\text { Proportion (\%) in } \\
\text { each group }\end{array}$} & Height & Leg length & Sitting height \\
\hline & & \multicolumn{3}{|l|}{ (cm) } \\
\hline \multicolumn{5}{|l|}{ Birth year } \\
\hline 1924 and earlier & 0.9 & 149.3 & 70.2 & 79.1 \\
\hline $1925-9$ & 4.9 & 150.5 & 70.7 & 79.9 \\
\hline $1930-4$ & 18.3 & 151.6 & 70.7 & 80.9 \\
\hline $1935-9$ & 27.5 & 152.4 & 70.6 & 81.8 \\
\hline $1940-4$ & 25.0 & 153.1 & 70.5 & 82.6 \\
\hline $1945-9$ & 25.9 & 154.0 & 70.6 & 83.4 \\
\hline $1950->$ & 0.9 & 155.6 & 71.3 & 84.3 \\
\hline$p$ Value for linear trend* & & $<0.001$ & 0.93 & $<0.001$ \\
\hline \multicolumn{5}{|l|}{ Highest educational level (years) } \\
\hline Less than primary $(\sim 0.5)$ & 17.1 & 151.4 & 70.6 & 80.8 \\
\hline Primary $(\sim 6)$ & 40.3 & 153.5 & 70.5 & 82.0 \\
\hline Junior middle school $(\sim 9)$ & 22.1 & 153.2 & 70.6 & 82.6 \\
\hline Senior middle school $(\sim 12)$ & 15.0 & 153.7 & 70.7 & 83.1 \\
\hline Senior technical college $(\sim 15)$ & 3.2 & 154.4 & 70.8 & 83.5 \\
\hline University $(\sim 16)$ & 2.4 & 154.3 & 71.0 & 83.3 \\
\hline $\mathrm{p}$ Value for linear trend* & & $<0.001$ & 0.12 & $<0.001$ \\
\hline \multicolumn{5}{|l|}{ Father's job } \\
\hline Manual & 76.2 & 152.7 & 70.6 & 82.1 \\
\hline Non-manual & 23.8 & 152.9 & 70.5 & 82.4 \\
\hline $\mathrm{p}$ Value & & 0.64 & 0.41 & 0.07 \\
\hline \multicolumn{5}{|l|}{ Age of menarche (years) } \\
\hline$\leqslant 12$ & 6.4 & 152.1 & 69.6 & 82.5 \\
\hline 13 & 14.7 & 152.7 & 70.2 & 82.5 \\
\hline 14 & 15.2 & 152.8 & 70.4 & 82.4 \\
\hline 15 & 18.1 & 152.5 & 70.4 & 82.2 \\
\hline 16 & 17.2 & 153.1 & 70.4 & 82.3 \\
\hline 17 & 11.7 & 153.2 & 70.7 & 82.1 \\
\hline 18 & 10.8 & 152.7 & 71.1 & 81.7 \\
\hline $19+$ & 6.0 & 152.5 & 71.3 & 81.2 \\
\hline$p$ Value for linear trend* & & 0.09 & $<0.001$ & $<0.001$ \\
\hline
\end{tabular}


Figure 2 Structural equation models with corresponding correlation coefficients for models relating childhood conditions to components of height, without (model a) and with (model b) age of menarche included, for 7273 women in the Guangzhou Biobank Cohort Study.
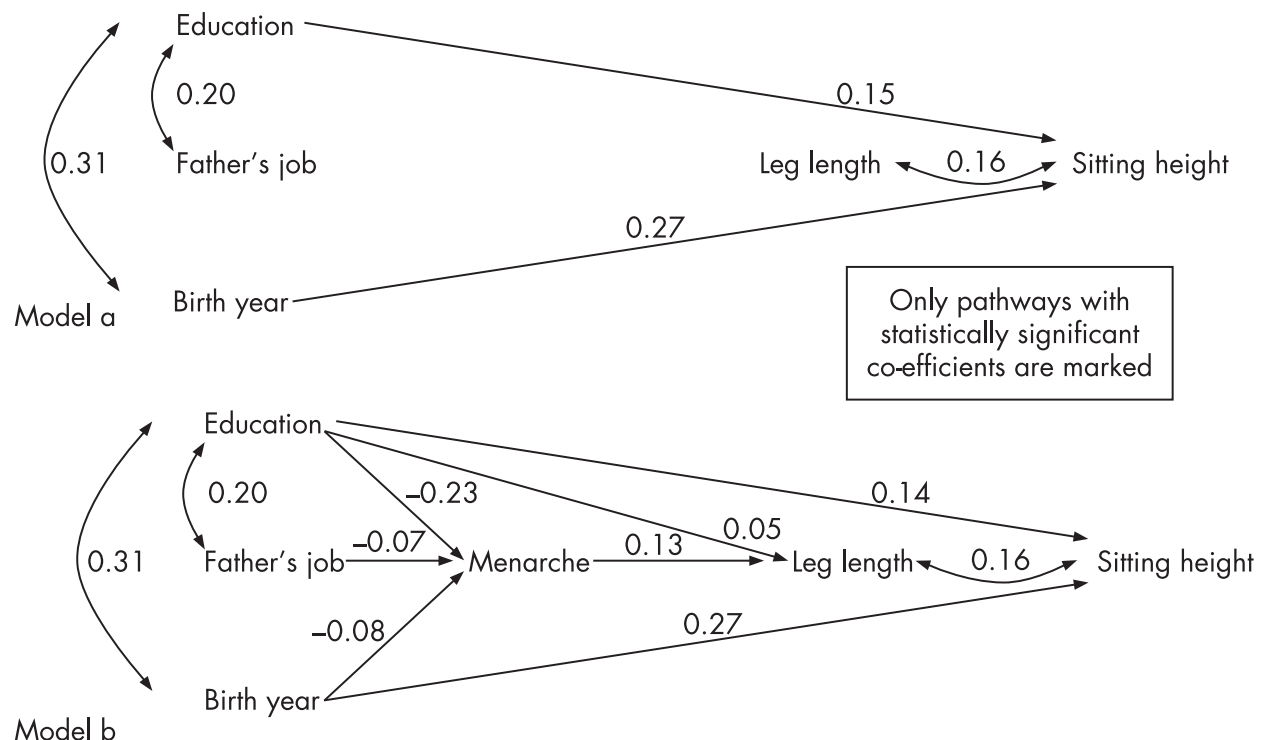

statistically significant, nor was a comparison between the two most educated groups and the rest ( $p$ value 0.09). Father's job was not associated with leg length. In contrast, younger age and more education were associated with greater height and greater sitting height. In addition, younger age of menarche was statistically significantly associated with shorter legs and greater sitting height.

Figure 2 shows the interrelationships between childhood conditions, age and components of height, without age of menarche (model a) and including age of menarche (model b), from an SEM using observed variables. For clarity only pathways with statistically significant correlation coefficients $(p<0.05)$ are marked and their correlation coefficients given. The corresponding regression coefficients with their 95\% CI are in table 2 (model b only).

Without considering age of menarche (model a), leg length was unrelated to education, father's job or birth year, but increased sitting height was associated with more education and later birth year. After including age of menarche (model b), more education was significantly associated with longer legs: $0.45 \mathrm{~cm}$ longer per additional 10 years of education $(95 \% \mathrm{CI}$ 0.20 to 0.71 ). More education, a non-manual father and later birth year (ie younger age) were also associated with younger age of menarche. Age of menarche was 1.21 years younger $(95 \%$ CI 1.09 to 1.34 ) per additional 10 years of education, 0.32 years younger ( $95 \%$ CI 0.16 to 0.48 ) for those with non-manual rather than manual fathers and 0.28 years younger per decade of birth later (95\% CI 0.20 to 0.36 ). Younger age of menarche was in turn associated with shorter legs: $0.23 \mathrm{~cm}$ shorter (95\% CI 0.18 to 0.27 ) per year of menarche earlier. The association of better childhood conditions with younger age of menarche, and in turn shorter legs, thus obscured the relationship between better childhood conditions and longer legs, which only became apparent when age of menarche was included (model b). There was no evidence of different associations by age group $(<65$ or $\geqslant 65$ years) in model $b$, in which $p$ values for the interaction term of education with age group were more than 0.3 for menarche, more than 0.9 for leg length and greater than 0.5 for sitting height.

Models with childhood conditions as a latent variable dependent on education, father's job and year of birth produced broadly similar results. These models did not, however, fit well and were not investigated further.

Models using all participants with complete data produced similar results, as did models without father's occupation (see appendix 1).

\section{DISCUSSION}

In this cohort of women, better childhood conditions, proxied by own education and father's occupation, were associated with greater sitting height and younger age of menarche. Better childhood conditions were not apparently directly associated with leg length, because these same exposures were also associated with younger age of menarche, which resulted in

Table 2 Changes in age of menarche and components of height with education, father's job and age in 7273 Chinese women in the Guangzhou Biobank Cohort Study in the full model including age of menarche (model b)

\begin{tabular}{|c|c|c|c|c|c|c|}
\hline & \multicolumn{2}{|l|}{ Age of menarche } & \multicolumn{2}{|l|}{ Leg length } & \multicolumn{2}{|l|}{ Sitting height } \\
\hline & $\begin{array}{l}\text { Difference (years) } \\
(95 \% \mathrm{CI})\end{array}$ & $\begin{array}{l}\text { Correlation } \\
\text { coefficient }\end{array}$ & $\begin{array}{l}\text { Difference }(\mathrm{cm}) \\
(95 \% \mathrm{CI})\end{array}$ & $\begin{array}{l}\text { Correlation } \\
\text { coefficient }\end{array}$ & $\begin{array}{l}\text { Difference }(\mathrm{cm}) \\
(95 \% \mathrm{CI})\end{array}$ & $\begin{array}{l}\text { Correlation } \\
\text { coefficient }\end{array}$ \\
\hline Education (per 10 years) & $-1.21(-1.34$ to -1.09$)$ & -0.23 & $0.45(0.20$ to 0.71$)$ & 0.05 & $1.16(0.94$ to 1.37$)$ & 0.14 \\
\hline $\mathrm{p}$ Value & & $<0.001$ & & $<0.001$ & & $<0.001$ \\
\hline Father's job (non-manual compared with manual) & l) $-0.32(-0.48$ to -0.16$)$ & -0.07 & $-0.09(-0.43$ to 0.24$)$ & -0.01 & $0.07(-0.22$ to 0.35$)$ & 0.01 \\
\hline $\mathrm{p}$ Value & & $<0.001$ & & 0.57 & & 0.64 \\
\hline Birth year (per decade younger) & $-0.28(-0.36$ to -0.20$)$ & -0.08 & $-0.07(-0.10$ to 0.23$)$ & 0.01 & $1.47(1.35$ to 1.60$)$ & 0.27 \\
\hline $\mathrm{p}$ Value & & $<0.001$ & & 0.42 & & $<0.001$ \\
\hline Age of menarche (per year older) & & & $0.23(0.18$ to 0.27$)$ & 0.13 & $-0.02(-0.06$ to 0.01$)$ & -0.02 \\
\hline p Value & & & & $<0.001$ & & 0.18 \\
\hline
\end{tabular}

Cl, Confidence interval. 
shorter legs. Once age of menarche was included in the structural equation model, higher levels of education were associated with longer legs.

Our observation that earlier menarche was associated with shorter legs is long known, ${ }^{35}$ supported by evidence from large numbers of women, ${ }^{36}$ and is biologically plausible, through the biphasic action of oestrogen. Low levels of oestrogen promote growth; higher levels cause the epiphyses to fuse and growth of the long bones in particular to cease. ${ }^{15}$

Our observation that higher socioeconomic status was associated with earlier menarche is consistent with observations from Hong Kong, which was largely peopled after 1945 by migrants from Guangzhou or the surrounding province of Guangdong. In girls from approximately the same birth years as this cohort, younger age of menarche was associated with higher parental socioeconomic status. ${ }^{14}$

On the other hand, our finding that the effect of better childhood conditions on leg length was masked by the same set of environmental exposures promoting earlier menarche is unique. To our knowledge no previous studies have examined the relationship between adult leg length, age of menarche and childhood conditions in societies at a similarly early stage of economic development as this cohort. We know of no studies investigating the validity of own education and father's occupation as proxies of childhood conditions in a similar setting. Childhood diet, clothing and housing or parental resources such as a bicycle, watch or sewing machine might be better proxies. We cannot rule out the possibility that our findings are a result of the inadequacies of our proxies of childhood conditions, although these proxies were associated with younger age of menarche, and intergenerational maintenance of privilege remains in China. ${ }^{31} 3237$

Historically, trends in age of menarche and height have been "strikingly different", 6 with falls in age of menarche taking place over a shorter time span than increases in height. These different time trends at an ecological level are consistent with better living conditions preferentially promoting earlier sexual maturity at the early stages of economic development. In the early stages of industrialisation in the west in the late 18th and early 19th century height unexpectedly stagnated or declined, which has been interpreted as individual living conditions declining contrary to average levels, ${ }^{38}{ }^{39}$ but could also have been because better living conditions produced earlier sexual maturity rather than greater height.

The precise mechanisms controlling linear growth and the onset of puberty are poorly understood. Age and size at maturity are life history traits, with developmental plasticity and susceptibility to environmentally determined trade-offs. ${ }^{40}$ Animal experiments show that maternal nutrition can impact growth and health over several subsequent generations. ${ }^{41}$ Epigenetic mechanisms have evolved to maximise maternaloffspring co-adaptations, which in species in which the offspring require maternal resources postnatally would include the regulation of postnatal as well as prenatal growth. ${ }^{42} 43$ Epigenetically determined growth regulation during early life

\section{Policy implications}

Research from long-term industrialised countries may not translate to other settings. Much more attention should be paid to the social and historical setting in which studies are carried out and how this might impact the findings. growth phases could take several generations to "wear off". In the ethnically similar but economically developed population of Hong Kong, growth faltering has been observed during late infancy. ${ }^{44}$

We speculate that epigenetic influences operating in early life may restrain linear growth in women from very recently developed populations, making leg length a less good biomarker of early life conditions. Instead, biomarkers of childhood conditions may be epidemiologically stage specific, with leg length more sensitive at later stages of economic development, and age of menarche more sensitive at earlier stages. These speculations have corresponding implications for interpreting the impact of childhood conditions on cardiovascular risk. In recently developed populations, a lack of association between leg length and cardiovascular risk, as has been observed ${ }^{45} 46$ (different from the protective effect in long-term industrialised countries), ${ }^{47-51}$ does not necessarily imply that better childhood conditions are not protective. On the other hand, investigation of the impact of age of menarche on cardiovascular risk in these recently developed populations could provide key aetiological insights, in particular, if as in long-term industrialised countries early puberty is associated with increased cardiovascular risk. ${ }^{52-55}$

\section{Limitations}

There are a number of potential limitations. First, leg length may be more prone to measurement error than sitting height, as it was calculated as the difference between standing and sitting height, each with their own variances, which would attenuate associations, for which our large sample compensates. Second, women recalled age of menarche, with its usual caveat of reporting bias, and caution in its interpretation. ${ }^{56}$ Random misclassification would again attenuate associations. Third, we used SEM, although one measure of childhood conditions was dichotomous. SEM is usually robust to violations of its assumptions in large samples. In addition, we could not obtain a well fitting SEM model with childhood conditions as a latent variable based on our proxies, possibly because what they represent is too disparate, hence our presentation of a model based on directly observed variables, with the advantages of simplicity and ease of interpretation. We did not have complete information on father's occupation, so we used multiple imputation, which uses all available data, preserves uncertainty from missing data, ${ }^{57}$ minimises inclusion bias and increases statistical power. ${ }^{33}$ Fourth, survival bias is possible. We found no effect modification by age group ( $<65$ years and $\geqslant 65$ years). Finally, our findings may be specific to this ethnic group, the

\section{What this study adds}

- In developed western populations longer legs have been shown to be a biomarker of better early childhood conditions. In transitioning populations better childhood conditions could also bring forward puberty and with it decreased leg length

- In older Chinese women better childhood conditions proxied by father's job and education were unrelated to leg length, because these same exposures were also associated with earlier menarche

- Leg length may not be a universal biomarker of childhood conditions. Given the impact of childhood conditions on long term health, and the dearth of long-term records outside the industrialised world a greater understanding of growth and development in the developing world is required 
stage of epidemiological transition and inevitably to women. We collected no marker of age at sexual maturity in the men, such as timing of first nocturnal emission or voice change.

\section{CONCLUSION}

In a large cohort of older Chinese women, who are one of the first generations to experience economic development, age of menarche rather than leg length appeared to be a biomarker of childhood conditions, when proxied by own education and father's occupation. We speculate that epigenetic influences originating with nutrition in earlier generations may constrain growth. That leg length may not always be a good marker of childhood conditions has implications for interpreting the observed associations between longer legs and lower cardiovascular risk.

Acknowledgements: The Guangzhou Biobank Cohort Study investigators include: Guangzhou No. 12 Hospital: XO Lao, WS Zhang, M Cao, T Zhu, B Liu, CQ Jiang (coprincipal investigator); University of Hong Kong: GN Thomas, CM Schooling, SM McGhee, RF Fielding, GM Leung, TH Lam (co-principal investigator); University of Birmingham: P Adab, Y Peng, KK Cheng (co-principal investigator). The authors would also like to thank Professor Sir R Peto and Dr Z M Chen of the Clinical Trial Service Unit, University of Oxford for their support.

Funding: The study was funded by the University of Hong Kong Foundation for Development and Research, and the University of Hong Kong University Research Committee Strategic Research Theme Public Health, Hong Kong; Guangzhou Public Health Bureau, and Guangzhou Science and Technology Bureau, Guangzhou, China; and the University of Birmingham, UK. The funding sources had no role in any of the following: study design; collection, analysis, and interpretation of data; the writing of the report; and the decision to submit the paper for publication.

Competing interests: None declared.

\section{REFERENCES}

1. Ben Shlomo Y, Kuh D. A life course approach to chronic disease epidemiology: conceptual models, empirical challenges and interdisciplinary perspectives. Int J Epidemiol 2002;31:285-93.

2. Kuh D, Ben-Shlomo Y. A life course approach to chronic disease epidemiology. Oxford: Oxford University Press, 1997

3. Billewicz WZ, Thomson AM, Fellowes HM. A longitudinal study of growth in Newcastle upon Tyne adolescents. Ann Hum Biol 1983;10:125-33.

4. Gunnell DJ, Smith GD, Frankel SJ, et al. Socio-economic and dietary influences on leg length and trunk length in childhood: a reanalysis of the Carnegie (Boyd Orr) survey of diet and health in prewar Britain (1937-39). Paediatr Perinat Epidemiol 1998;12(Suppl 1):96-113

5. Wadsworth ME, Hardy RJ, Paul AA, et al. Leg and trunk length at 43 years in relation to childhood health, diet and family circumstances; evidence from the 1946 national birth cohort. Int J Epidemiol 2002;31:383-90.

6. Cole TJ. Secular trends in growth. Proc Nutr Soc 2000;59:317-24.

7. Karlberg J. Secular trends in pubertal development. Horm Res 2002;57(Suppl 2):19-30.

8. Smith DG, Hart C, Upton M, et al. Height and risk of death among men and women: aetiological implications of associations with cardiorespiratory disease and cancer mortality. J Epidemiol Community Health 2000;54:97-103.

9. Gunnell D, Okasha M, Smith GD, et al. Height, leg length, and cancer risk: a systematic review. Epidemiol Rev 2001;23:313-42.

10. Cavelaars $\mathbf{A E}$, Kunst $A \mathrm{E}$, Geurts JJ, et al. Persistent variations in average height between countries and between socio-economic groups: an overview of 10 European countries. Ann Hum Biol 2000;27:407-21.

11. Kuh DL, Power C, Rodgers B. Secular trends in social class and sex differences in adult height. Int J Epidemiol 1991;20:1001-9.

12. Junqueira Do LM, Faerstein E, De Souza LC, et al. Family socio-economic background modified secular trends in age at menarche: evidence from the Pro-Saude Study (Rio de Janeiro, Brazil). Ann Hum Biol 2003;30:347-52.

13. Low WD, Kung LS, Leong JC. Secular trend in the sexual maturation of Chinese girls. Hum Biol 1982;54:539-51.

14. Lee MM, Chang KS, Chan MM. Sexual maturation of Chinese girls in Hong Kong. Pediatrics 1963;32:389-98.

15. Alonso LC, Rosenfield RL. Oestrogens and puberty. Best Pract Res Clin Endocrinol Metab 2002;16:13-30.

16. Juul A. The effects of oestrogens on linear bone growth. Hum Reprod Update 2001;7:303-13.

17. Mul D, Oostdijk W, Drop SL. Early puberty in adopted children. Horm Res 2002;57:1-9.

18. Teilmann G, Pedersen CB, Skakkebaek NE, et al. Increased risk of precocious puberty in internationally adopted children in Denmark. Pediatrics 2006;118:e391-9.

19. Papadimitriou A, Beri D, Tsialla A, et al. Early growth acceleration in girls with idiopathic precocious puberty. J Pediatr 2006;149:43-6.
20. Eckstein A. China's economic development. Ann Arbor: University of Michigan, 1975.

21. Maddison A. Chinese economic performance in the long run. Paris: OECD, 1998.

22. Brandt L. Reflections on China's late 19th and early 20th-century economy. China Quarterly 1997;150:282-308.

23. Rawski T. Economic growth in pre-war China. Berkeley: University of California Press, 1990.

24. Ngo TW. Industrial history and the artiface of laissez-faire colonialism. In: Faure D, ed Hong Kong: a reader in social history. Oxford: Oxford University Press, 2003:543-71.

25. Komlos J. An anthropometric history of early-modern France. Eur Rev Econ Hist 2003; 7:159-89.

26. Shirokogorov SM. Anthropology of eastern China and Kwangtung Province. Shanghai: Royal Asiatic Societyof Great Britian and Ireland North China Branch, 1925.

27. Cadbury WW. Height, weight and chest measurements of Mongolian Peoples with especial reference to Southern Chinese. Philippine J Sci 1924;25:733-59.

28. Stevenson PH. Collected anthropomteric data on the Chinese. China Med J 1925;XXXIX:855-98.

29. Jiang C, Thomas GN, Lam TH, et al. Cohort profile: the Guangzhou Biobank Cohort Study, a Guangzhou-Hong Kong-Birmingham collaboration. Int J Epidemiol 2006;35:844-52.

30. Buchmann C, Hannum E. Education and stratification in developing countries a review of theories and research. Annu Rev Sociol 2001;27:77-102.

31. Whyte MK, Parish WL. Urban life in contemporary China. Chicago: University of Chicago Press, 1984.

32. Deng Zhong, Treiman DJ. The impact of the Cultural Revolution on trends in educational attainment in the People's Republic of China. AJS 1997;103:391-428.

33. Schafer JL. Multiple imputation: a primer. Stat Methods Med Res 1999:8:3-15.

34. Harrell FE. Regression modeling strategies: with applications to linear models, logistic regression, and survival analysis. New York: Springer Verlag, 2001.

35. Duval-Beaupere G. Growth of the trunk and lower limbs after the menarche. Rev Chir Orthop Reparatrice Appar Mot 1976;62:501-9.

36. Onland-Moret NC, Peeters PH, van Gils CH, et al. Age at menarche in relation to adult height: the EPIC study. Am J Epidemiol 2005;162:623-32.

37. Hannum E. Poverty and basic education in rural China: villages, households, and girls and boys' enrollment. Comp Educ Rev 2003;47:141-59.

38. Komlos J. Anomalies in economic history: toward a resolution of the "antebellum puzzle". J Econ Hist 1996;56:202-14.

39. Komlos J. Shrinking in a growing economy? the mystery of physical stature during the industrial revolution. J Econ Hist 1998;58:779-802.

40. Stearns SC. Life-history tactics: a review of the ideas. O Rev Biol 1976;51:3-47.

41. Cropley JE, Suter CM, Beckman KB, et al. Germ-line epigenetic modification of the murine A vy allele by nutritional supplementation. Proc Natl Acad Sci U S A 2006;103:17308-12.

42. Wood AJ, Oakey RJ. Genomic imprinting in mammals: emerging themes and established theories. PLoS Genet 2006;2:e147.

43. Wolf JB, Hager R. A maternal-offspring coadaptation theory for the evolution of genomic imprinting. PLoS Biol 2006;4:e380.

44. Davies DP, Leung SS. Growth of Hong Kong infants during the first two years of life. Early Hum Dev 1985;11:247-54.

45. Langenberg C, Araneta MR, Bergstrom J, et al. Diabetes and coronary heart disease in Filipino-American women: role of growth and life-course socioeconomic factors. Diabetes Care 2007;30:535-41.

46. Schooling CM, Jiang C, Lam TH, et al. Height, its components and cardiovascular risk in older Chinese: a cross-sectional analysis of the Guangzhou Biobank Cohort Study. Am J Public Health 2007;97:1834-41.

47. Gunnell DJ, Smith GD, Frankel S, et al. Childhood leg length and adult mortality: follow up of the Carnegie (Boyd Orr) Survey of Diet and Health in Pre-war Britain. $J$ Epidemiol Community Health 1998;52:142-52.

48. Smith GD, Greenwood R, Gunnell DJ, et al. Leg length, insulin resistance, and coronary heart disease risk: the Caerphilly Study. J Epidemiol Community Health 2001;55:867-72.

49. Gunnell D, Whitley E, Upton MN, et al. Associations of height, leg length, and lung function with cardiovascular risk factors in the Midspan Family Study. J Epidemiol Community Health 2003;57:141-6.

50. Langenberg C, Hardy R, Kuh D, et al. Influence of height, leg and trunk length on pulse pressure, systolic and diastolic blood pressure. J Hypertens 2003;21:537-43.

51. Lawlor DA, Taylor M, Smith GD, et al. Associations of components of adult heigh with coronary heart disease in postmenopausal women: the British women's heart and health study. Heart 2004;90:745-9.

52. Remsberg KE, Demerath EW, Schubert CM, et al. Early menarche and the development of cardiovascular disease risk factors in adolescent girls: the Fels Longitudinal Study. J Clin Endocrinol Metab 2005;90:2718-24.

53. Hardy R, Kuh D, Whincup PH, et al. Age at puberty and adult blood pressure and body size in a British birth cohort study. J Hypertens 2006;24:59-66.

54. Frontini MG, Srinivasan SR, Berenson GS. Longitudinal changes in risk variables underlying metabolic syndrome $X$ from childhood to young adulthood in female subjects with a history of early menarche: the Bogalusa Heart Study. Int J Obes Relat Metab Disord 2003;27:1398-404.

55. Pierce MB, Leon DA. Age at menarche and adult BMl in the Aberdeen children of the 1950s cohort study. Am J Clin Nutr 2005;82:733-9.

56. Cooper R, Blell M, Hardy R, et al. Validity of age at menarche self-reported in adulthood. J Epidemiol Community Health 2006;60:993-7.

57. Little RJA, Rubin DB. Statistical analysis with missing data. Hoboken: Wiley, 2002 


\section{Research report}

\section{Appendix 1}

\section{Complete case analysis}

\section{Analysis without using father's occupation}

Figure A3 Structural equation models with corresponding correlation coefficients for models relating childhood conditions to components of height, without (model a) and with (model b) age of menarche included, for 3676 women with complete data in the Guangzhou Biobank Cohort Study.
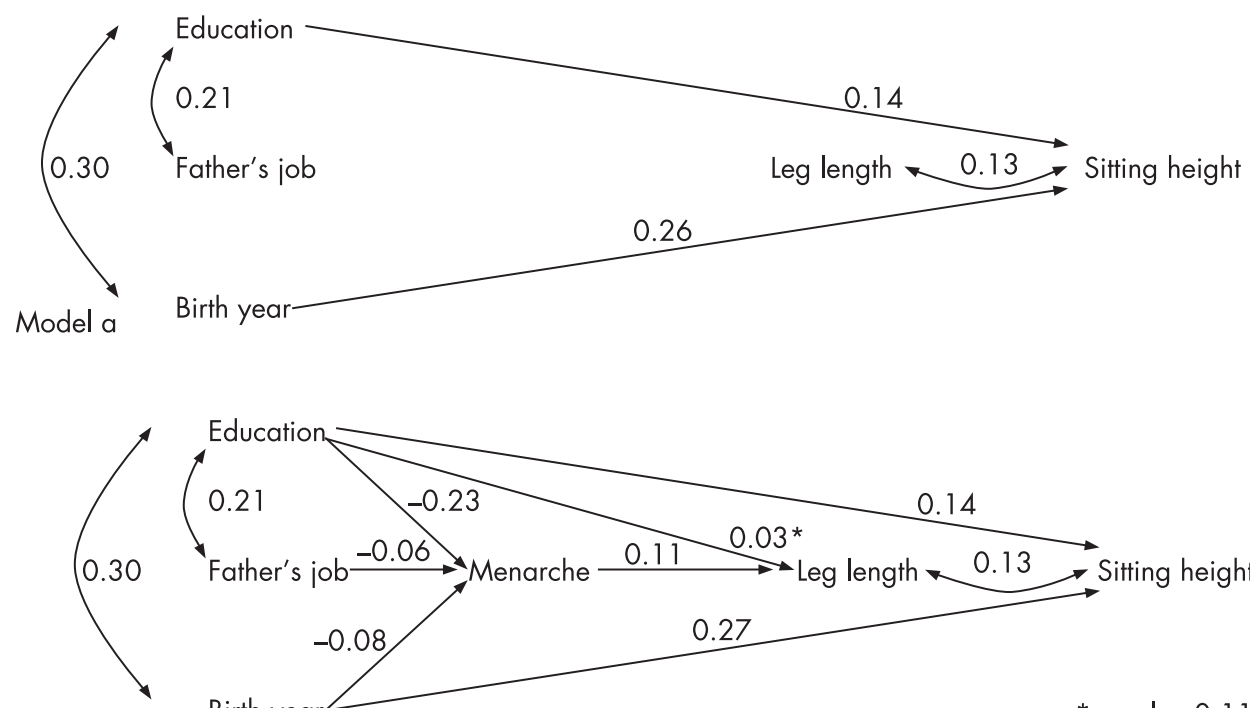

Model b

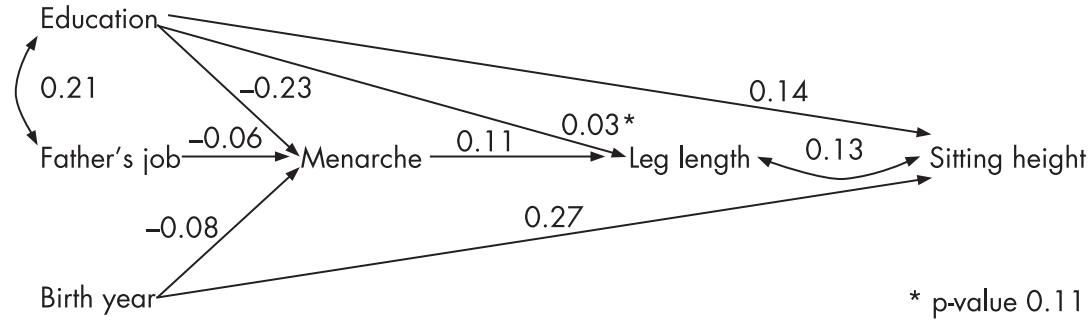

Table A3 Changes in age of menarche and components of height with education, father's job and age for 3676 Chinese women with complete data in the Guangzhou Biobank Cohort Study in the full model including age of menarche (model b)

\begin{tabular}{|c|c|c|c|c|c|c|}
\hline & \multicolumn{2}{|l|}{ Age of menarche } & \multicolumn{2}{|l|}{ Leg length } & \multicolumn{2}{|l|}{ Sitting height } \\
\hline & $\begin{array}{l}\text { Difference (years) } \\
(95 \% \mathrm{CI})\end{array}$ & $\begin{array}{l}\text { Correlation } \\
\text { coefficient }\end{array}$ & $\begin{array}{l}\text { Difference }(\mathrm{cm}) \\
(95 \% \mathrm{Cl})\end{array}$ & $\begin{array}{l}\text { Correlation } \\
\text { coefficient }\end{array}$ & $\begin{array}{l}\text { Difference }(\mathrm{cm}) \\
(95 \% \mathrm{CI})\end{array}$ & $\begin{array}{l}\text { Correlation } \\
\text { coefficient }\end{array}$ \\
\hline Education (per 10 years) & $-1.21(-1.39$ to -1.04$)$ & -0.23 & $0.28(-0.06$ to 0.62$)$ & 0.03 & $1.15(0.87$ to 1.42$)$ & 0.14 \\
\hline $\mathrm{p}$ Value & & $<0.001$ & & 0.11 & & $<0.001$ \\
\hline $\begin{array}{l}\text { Father's job (non-manual } \\
\text { compared with manual) }\end{array}$ & $-0.29(-0.45$ to -0.14$)$ & -0.06 & $-0.07(-0.36$ to 0.23$)$ & -0.01 & $0.10(-0.15$ to 0.34$)$ & 0.01 \\
\hline $\mathrm{p}$ Value & & $<0.001$ & & 0.67 & & 0.42 \\
\hline $\begin{array}{l}\text { Birth year (per decade } \\
\text { younger) }\end{array}$ & $-0.27(-0.38$ to -0.15$)$ & -0.08 & $0.08(-0.14$ to 0.29$)$ & 0.01 & $1.42(1.24$ to 1.60$)$ & 0.27 \\
\hline $\mathrm{p}$ Value & & $<0.001$ & & 0.48 & & $<0.001$ \\
\hline $\begin{array}{l}\text { Age of menarche (per year } \\
\text { older) }\end{array}$ & & & $0.20(0.14$ to 0.26$)$ & 0.11 & $-0.03(-0.08$ to 0.02$)$ & -0.02 \\
\hline $\mathrm{p}$ Value & & & & $<0.001$ & & 0.22 \\
\hline
\end{tabular}

Cl, Confidence interval. 
Figure A4 Structural equation models with corresponding correlation coefficients for models relating childhood conditions, proxied by education, to components of height, without (model a) and with (model b) age of menarche included, for 7273 women in the Guangzhou Biobank Cohort Study.

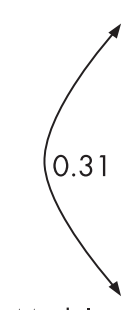

Education
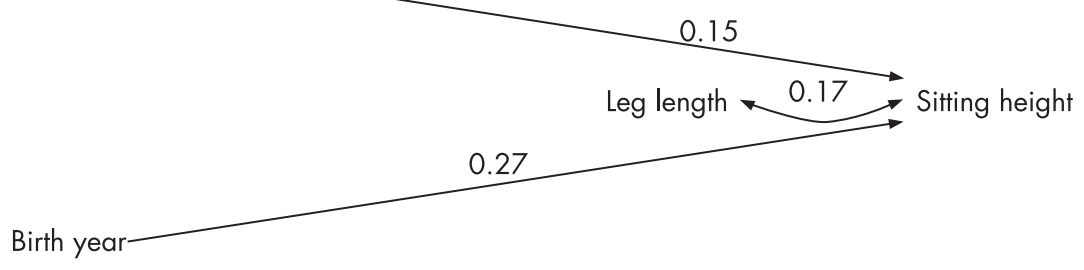

0.27

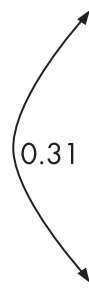

Model b

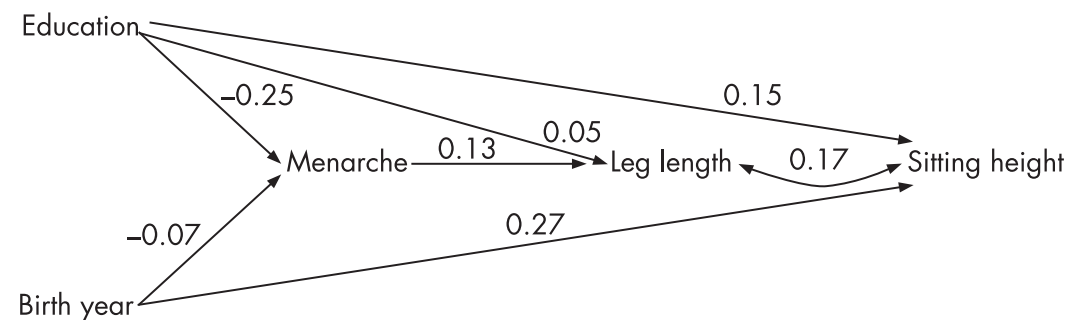

Table A4 Changes in age of menarche and components of height with education and age in 7273 Chinese women in the Guangzhou Biobank Cohort Study in the full model including age of menarche (model b)

\begin{tabular}{|c|c|c|c|c|c|c|}
\hline & \multicolumn{2}{|l|}{ Age of menarche } & \multicolumn{2}{|l|}{ Leg length } & \multicolumn{2}{|l|}{ Sitting height } \\
\hline & $\begin{array}{l}\text { Difference (years) } \\
(95 \% \mathrm{CI})\end{array}$ & $\begin{array}{l}\text { Correlation } \\
\text { coefficient }\end{array}$ & $\begin{array}{l}\text { Difference (cm) } \\
(95 \% \mathrm{Cl})\end{array}$ & $\begin{array}{l}\text { Correlation } \\
\text { coefficient }\end{array}$ & $\begin{array}{l}\text { Difference (cm) } \\
(95 \% \mathrm{CI})\end{array}$ & Correlation coefficient \\
\hline $\begin{array}{l}\text { Education (per } 10 \text { years) } \\
\text { p Value }\end{array}$ & $-1.29(-1.41$ to -1.17$)$ & $\begin{array}{l}-0.25 \\
<0.001\end{array}$ & $0.43(0.20$ to 0.66$)$ & $\begin{aligned} & 0.05 \\
< & 0.001\end{aligned}$ & $1.17(0.96$ to 1.36$)$ & $\begin{array}{c}0.15 \\
<0.001\end{array}$ \\
\hline Birth year (per decade younger) & $-0.26(-0.34$ to -0.18$)$ & $\begin{array}{l}-0.07 \\
<0.001\end{array}$ & $0.07(-0.08$ to 0.22$)$ & $\begin{array}{l}0.01 \\
0.35\end{array}$ & $1.47(1.35$ to 1.59$)$ & $\begin{array}{c}0.27 \\
<0.001\end{array}$ \\
\hline $\begin{array}{l}\text { p Value } \\
\text { Age of menarche (per year } \\
\text { older) }\end{array}$ & & & 0.23 (0.18 to 0.27$)$ & 0.13 & $-0.03(-0.06$ to 0.01$)$ & -0.02 \\
\hline
\end{tabular}

Cl, Confidence interval. 